\title{
Nerve-sparing surgery and sexual and urinary dysfunction after multimodality treatment for rectal cancer
}

\author{
V. Celentano ${ }^{1}$
}

Received: 5 February 2017/Accepted: 7 February 2017/Published online: 16 February 2017

(C) Springer International Publishing AG 2017

\section{Dear Sir,}

I would like to thank Husher and Rossetti for demonstrating a purely anatomical approach to dissection of the inferior mesenteric artery during sigmoid colectomy with the use of the Cavitron Ultrasonic Surgical Aspirator (CUSA) (SonoSurg, Olympus, Tokyo, Japan) [1], where the sympathetic nerves of the superior hypogastric plexus are vulnerable to injury.

It is important to note that both sexual and urinary function are dependent on dual autonomic (sympathetic and parasympathetic) innervation, and damage to the preaortic nerve fibers and superior hypogastric plexus, during flush ligation of the inferior mesenteric artery, is only one of four danger zones that are 'at risk' of nerve damage during colorectal surgery [2].

Techniques and results of nerve-sparing surgery have been extensively reported [3], focusing on functional outcomes following rectal resection for several reasons. Firstly, the pelvic dissection, particularly during the anterior and lateral mobilization of the rectum, is where the damage to the autonomic nerves is most likely to occur, and it is where new techniques and devices are more likely to impact on functional results.

Secondly, sexual and urinary problems after surgery for rectal cancer are multifactorial [4], and other concomitant causes exist, such as preexisting comorbidities, radiotherapy and psychological factors. In fact, this is confirmed by the impossibility of eradicating the risk even when a full nerve-preserving operation is intended and documented

\section{Celentano}

valeriocelentano@yahoo.it

1 Colorectal Unit, Queen Alexandra Hospital, Portsmouth Hospitals NHS Trust, Portsmouth, UK
[5], or when the procedure is performed for non-oncological indications, or with the use of a sophisticated intraoperative neuromonitoring device [6].

\section{Compliance with ethical standards}

Conflict of interest The author declares that he has no conflict of interest.

Ethical approval For this type of study formal consent is not required.

Informed consent Informed consent was obtained from all indivdual participants included in the study.

\section{References}

1. Huscher CGS, Rossetti A (2017) Nerve-sparing high ligation of the inferior mesenteric artery with Cavitron ultrasonic surgical aspirator (CUSA). Tech Coloproctol. doi:10.1007/s10151-016-1574-8

2. Lindsey I, Guy RJ, Warren BF et al (2000) Anatomy of Denonvilliers' fascia and pelvic nerves, impotence, and implications for the colorectal surgeon. Br J Surg 87(10):1288-1299

3. Lim RS, Yang TX, Chua TC (2014) Postoperative bladder and sexual function in patients undergoing surgery for rectal cancer: a systematic review and meta-analysis of laparoscopic versus open resection of rectal cancer. Tech Coloproctol 18:993

4. Hendren SK, O'Connor BI, Liu M et al (2005) Prevalence of male and female sexual dysfunction is high following surgery for rectal cancer. Ann Surg 242(2):212-223

5. Celentano V, Fabbrocile G, Luglio G et al (2010) Prospective study of sexual dysfunction in men with rectal cancer: feasibility and results of nerve sparing surgery. Int $\mathrm{J}$ Colorectal Dis 25(12):1441-1445

6. Kauff DW, Kneist W et al (2016) Electrophysiology-based quality assurance of nerve-sparing in laparoscopic rectal cancer surgery: is it worth the effort? Surg Endosc 30(10):4525-4532 